\title{
Association in Dilute Aqueous Solution of Pyridine and Its Methyl Derivatives Studied by Cryoscopic Method
}

\author{
Kamila Serwicka • Wojciech Marczak
}

Received: 27 April 2010 / Accepted: 12 July 2010 / Published online: 25 July 2010

(C) The Author(s) 2010. This article is published with open access at Springerlink.com

\begin{abstract}
Pyridine and its methyl derivatives form complexes with water due to hydrogen bonds. The co-operative nature of the hydrogen bonds leads to the association of the complexes and to various modes of hydration. The degrees of association of monohydrate complexes have been calculated for liquid dilute aqueous solutions of pyridine, 2-, 3-, 4-methylpyridine, and 2,6-dimethylpyridine at temperatures from $273 \mathrm{~K}$ to $268.5 \mathrm{~K}$. The association number increases with an increase of the amine concentration. Positive correlation was found between the degree of association of the 1:1 water-amine complexes and the size of microheterogeneities. It was shown that the mechanics of this process involves hydrogen bonding and van der Waals interactions.
\end{abstract}

Keywords Aqueous solutions - Association - Freezing curves · Hydrogen bond · Pyridines $\cdot$ Solid-liquid equilibrium

\section{Introduction}

The formation of supermolecular structures in aqueous solutions of organic substances is one of the main subjects of physicochemical studies of liquid mixtures. It is well known that water is not an inert solvent, but rather interacts with solutes. A classical example is the mutarotation of glucopyranose: the ratio of $\alpha$-D-glucopyranose to $\beta$-D-glucopyranose changes from approximately 50:50 in the solid state and in inert solvents (e.g., pyridine or DMSO) to 36:64 in aqueous solution [1]. A subtle interplay between proteins and water is crucial for the existence of life. Information about complex interactions in natural systems can be gained from studies of model mixtures. Aqueous solutions of pyridine and its methyl derivatives are convenient and relatively

K. Serwicka $(\varangle) \cdot$ W. Marczak

Institute of Chemistry, University of Silesia, Szkolna 9, 40-006 Katowice, Poland

e-mail: kkielek@ich.us.edu.pl 
simple model systems for studies of hydration and association processes. A molecule of pyridine has an electron pair localized on the nitrogen atom that plays a role of the hydrogen acceptor. In binary mixtures with water, the amine molecules join those of water due to $\mathrm{O}-\mathrm{H} \ldots \mathrm{N}$ bonds stronger than the competing $\mathrm{O}-\mathrm{H}$...O bonds. Quantum chemistry calculations give an approximately $6.7 \mathrm{~kJ} \cdot \mathrm{mol}^{-1}$ difference between the energies of pyridine-water and water-water H-bonds [2]. Substitution of methyl groups for the hydrogen atoms in the ring leads to a further increase of that difference. The reinforcement is particularly pronounced for two $\mathrm{CH}_{3}$ groups in the ortho position towards the $\mathrm{N}$ atom. That was confirmed by the results of calorimetric experiment [3] and theoretical calculations [4].

Our previous studies showed that 2,6-dimethylpyridine forms 1:1 complexes with water in the solid state, $\mathrm{C}_{7} \mathrm{H}_{11} \mathrm{~N} \cdot \mathrm{H}_{2} \mathrm{O}$ [5]. The complexes remain stable even in the liquid phase, at least, in the vicinity of the hydrate melting point at $273 \mathrm{~K}$. Infrared spectra of this system reveal the association of complexes due to $\mathrm{O}-\mathrm{H}$...O bonds between water molecules (Fig. 1). Thus, the water molecule is bonded to one molecule of 2,6-dimethylpyridine, while its second proton can accept the electron pair of another molecule of $\mathrm{H}_{2} \mathrm{O}$. Similar limiting molar enthalpies of solution of methanol and water in pyridine, monomethylpyridines, and 2,6-dimethylpyridine suggest that one molecule of water joins a single amine molecule through the $\mathrm{O}-\mathrm{H}$... $\mathrm{N}$ bond $[3,6]$. Thus, there are still water protons capable of the $\mathrm{O}-\mathrm{H} . . . \mathrm{O}$ bonding even in the amine-rich mixtures.

Contrary to 2,6-dimethylpyrine, pyridine and 4-methylpyridine form solid trihydrates rather than monohydrates $[7,8]$. However, the pyridine trihydrate melts incongruently forming ice and a liquid aqueous solution of pyridine [9]. The latter may contain a monohydrate of pyridine. Most probably, 4-methylpyriridine trihydrate behaves in a similar way.

In the present study, we adopted the idea of association of the amine-water complexes to explain the depression of the freezing temperature of water caused by pyridines dissolved in the liquid phase. Since the depression is a colligative quantity, it would reflect the propensity of complexes to association and, in an indirect

Fig. 1 Hydrogen bonds between monohydrates of 2,6-dimethylpyridine

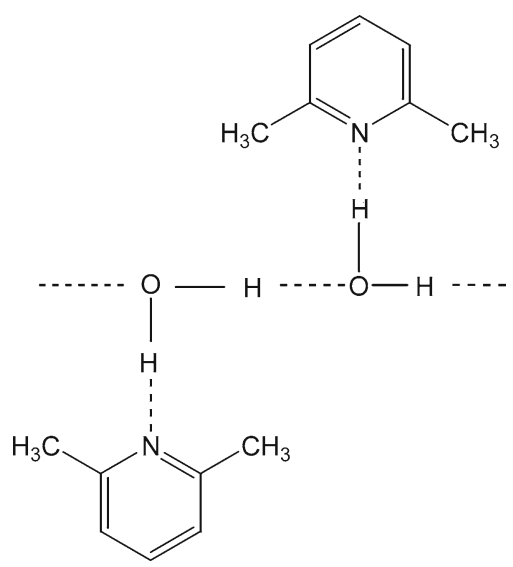


way, the strength of hydrogen bonds as well as the energy of other intermolecular interactions.

The well-known cryoscopic relation describes the equilibrium temperature of a solid solvent and a liquid solution as a function of the concentration [10]:

$$
\Delta T_{\mathrm{f}}=K c
$$

where $\Delta T_{\mathrm{f}}$ is a difference between the freezing temperatures of pure solvent and the solution, $\Delta T_{\mathrm{f}}=T_{\mathrm{f}}^{0}-T_{\mathrm{f}}, c$ is the molality of the solution (number of moles of the solute per kilogram of the solvent), and $K$ is a solvent-dependent cryoscopic constant. This formula is true for an ideally dilute binary liquid solution in equilibrium with a pure solid solvent. Thus, the solute must be insoluble in the solid solvent. That condition is undoubtedly met by pyridine and 2,6-dimethylpyridine [5,9] and most probably by the other pyridines too, since the molecules of all the amines are rather similar to one another. Another assumption, that the enthalpy of fusion does not depend on temperature, is fulfilled in this experiment because of the small depressions of the freezing temperature.

For the associated solutes, the depression of the freezing temperature is smaller than that calculated from the analytical concentration $c$ and reflects the degree of association. The concentration of associates can be easily calculated from Eq. 1, provided that the inert solvent does not participate in the aggregation. Otherwise, a molecular composition of the solute-solvent cross-associate must be known, because the concentration $c$ has to be expressed in terms of the actual entities present in the mixture.

Thus, we estimated the size of the water-amine aggregates using the cryoscopic approach to the experimentally measured depressions of the freezing temperatures. The results were discussed in terms of universal and specific intermolecular interactions.

\section{Experimental}

Binary systems containing water and the following amines were studied: pyridine, 2-methylpyridine, 3-methylpyridine, 4-methylpyridine, and 2,6-dimethylpyridine. The temperatures of fusion were measured with a differential scattering calorimeter TA Instruments DSC 2920 CE, while those of freezing were determined visually using a glass cell cooled by a cryostat. Experimental details were reported in our previous work [5].

The mixtures for the DSC experiment were prepared by mass, using an analytical balance. For the freezing-point experiments, the solutions were prepared volumetrically by successive dilutions.

\section{Calculations}

Degrees of association were determined for the five aqueous systems, in the amine mole fraction range from 0 to 0.12 . The analytical molalities of the 2,6-dimethylpyridine solutions and those calculated from Eq. 1 are plotted versus the experimental 


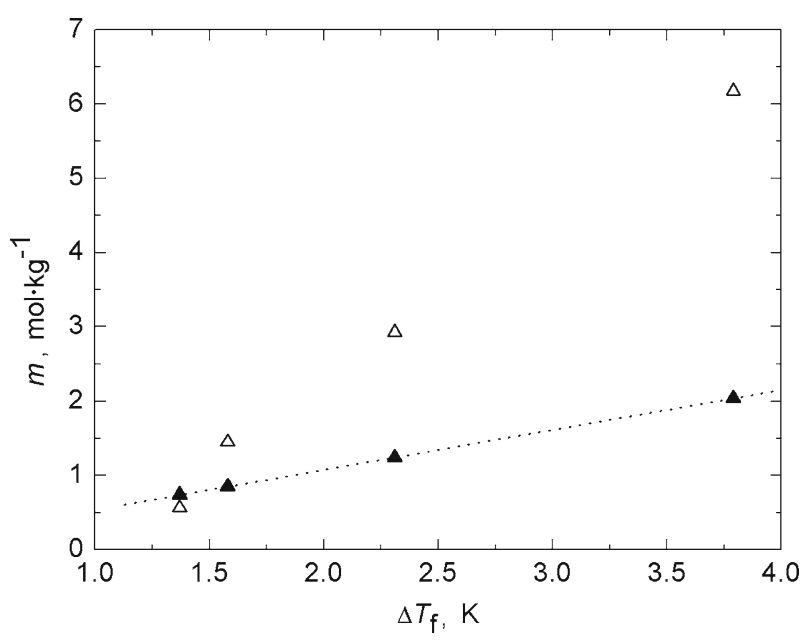

Fig. 2 Analytical molalities of the 2,6-dimethylpyridine solutions (open triangle) and those calculated from the cryoscopic formula (filled triangle) versus the experimental depression of the freezing temperature

depression of the freezing temperature in Fig. 2. A considerable difference between the two functions demonstrates evidence that the number of molecular entities diluted in the solvent is significantly smaller than the number of 2,6-dimethylpyridine molecules. Similar results were obtained for the other systems. Thus, the aggregation occurs in all the solutions studied. For the reasons explained in Sect. 1, we assumed that the pyridines form monohydrates and the latter undergo association through hydrogen bonds. Consequently, the concentrations had to be recalculated in order to express the system's composition in relation to the content of the monohydrates rather than of the unbonded amines. To this end, the mole fractions $X_{i}$ of water $(i=1)$ and the monohydrate $(i=2)$ were defined in the following way:

$$
\begin{aligned}
& X_{2}=x_{2} /\left(1-x_{2}\right) \\
& X_{1}=1-X_{2},
\end{aligned}
$$

where $x_{2}$ is the analytical mole fraction of amine. Then, the corrected molalities were calculated:

$$
C=X_{2} /\left(X_{1} M_{1}\right)
$$

where $M_{1}$ is the molar mass of water.

Since the depression of the freezing temperature never exceeded $4.5 \mathrm{~K}$, which changed the freezing enthalpy of water by just about $0.06 \%$, the cryoscopic formula could be applied. Thus, the average degree of association $\alpha$ of the monohydrates was expressed by the ratio of the corrected molality $C$ to its actual counterpart $C^{\mathrm{A}}$ calculated from Eq. 1: 


$$
\alpha=C / C^{\mathrm{A}}=X_{2} K_{\mathrm{f}} /\left(X_{1} M_{1} \Delta T\right) .
$$

As expected, the degrees of association obtained from Eq. 5 depended on concentration.

\section{Results and Discussion}

The experimental depressions of the freezing temperature and the degrees of association are collected in Table 1. For the comparison, the results for the pyridine system obtained from the literature data [9] were also reported. The agreement is pretty goodthe degrees of association of the pyridine monohydrate calculated from the literature data are just $12 \%$ higher than those calculated from our results. That difference is rather small in comparison with the $200 \%$ increase of $\alpha$ caused by the $X_{2}$ change from 0.01 to 0.12 . Figure 3 illustrates the influence of concentration on the association of monohydrates of pyridine and its derivatives. The degrees of association are slightly smaller than that in dilute solutions that may result from the dissociation of the amines. The latter are weak bases in an aqueous environment. At $X_{2}>0.1$, however, the effect vanishes and the association clearly predominates.

The propensity to association increases in the following order: py $\approx 2$-mpy $\leq$ 2,6-dmpy $<4$-mpy $\approx 3$-mpy. This series corresponds roughly to the size of microheterogeneities revealed by small-angle neutron scattering (SANS) [11,12]. Most probably, the microheterogeneities result from the aggregation of water-amine complexes thanks to the $\mathrm{O}-\mathrm{H}$... O bonds. Such aggregates of complexes would exist in the solvent that resembles bulk water. There is cogent, although indirect argument for that explanation. As evidenced by the SANS experiment, such aggregates do not arise in the methanolic solutions [13]. A molecule of methanol can form only one hydrogen bond as a donor of proton. Thus, the methanol-amine complexes are incapable of clustering because of the lack of proton-donating functional groups.

It seemed reasonable to combine the observed regularity in the degrees of association with the amine-water association energies. One could expect that the stronger were hydrogen bonds in the 1:1 amine-water complexes, and the larger were the aggregates, due to the H-bond co-operativity. However, such a simple relationship does not occur. That points to other intermolecular forces involved in the interactions, such as the $\pi-\pi$ and dipole-dipole attractions between the neighboring amine molecules. The association energies, as well as polarizability volumes and dipole moments necessary for estimation of the van der Waals forces, are collected in Table 2. It is evident that none of these interactions is decisive for the propensity to association.

Some information about the molecular order in liquid water-amine systems can be gained from crystal structures of solid hydrates. In the liquid system, remnants of the crystalline structures are in dynamic equilibrium with the less structured "fluid" phase. Unfortunately, only two relevant crystal structures are known: those of pyridine and 4-methylpyridine trihydrates $[7,8,18]$. In these structures, hydrogen-bonded water molecules form two-dimensional layers with protons protruding on either side, through which the amine molecules are connected. In that way, a sandwich arrangement arises. In the trihydrates, the neighboring 4-methylpyridine molecules are anti-parallel one to another, while those of pyridine are evidently skew (Fig. 4). That may result 
Table 1 Depressions of freezing temperature $\Delta T$ and degrees of association $\alpha$ (Eq.5) in binary aqueous solutions of pyridine (py) and its methyl derivatives: mpy—methylpyridine, dmpy—dimethylpyridine

\begin{tabular}{|c|c|c|c|c|c|}
\hline System & $x_{2}{ }^{\mathrm{a}}$ & $X_{2}{ }^{\mathrm{b}}$ & $\Delta T(\mathrm{~K})$ & $\alpha$ & Method \\
\hline \multirow[t]{14}{*}{$\mathrm{H}_{2} \mathrm{O}(1)+$ py $(2)$} & 0.0085 & 0.0086 & 1.0 & 0.89 & \multirow[t]{10}{*}{ Visual } \\
\hline & 0.0107 & 0.0108 & 1.0 & 1.13 & \\
\hline & 0.0144 & 0.0146 & 1.5 & 1.02 & \\
\hline & 0.0221 & 0.0226 & 2.0 & 1.19 & \\
\hline & 0.0301 & 0.0310 & 2.5 & 1.32 & \\
\hline & 0.0484 & 0.0509 & 3.0 & 1.84 & \\
\hline & 0.0586 & 0.0622 & 3.5 & 1.96 & \\
\hline & 0.0695 & 0.0747 & 4.0 & 2.08 & \\
\hline & 0.0793 & 0.0861 & 4.0 & 2.43 & \\
\hline & 0.1007 & 0.1120 & 4.5 & 2.89 & \\
\hline & 0.0120 & 0.0121 & 1.19 & 1.07 & \multirow[t]{4}{*}{ Visual, Ref. [9] } \\
\hline & 0.0250 & 0.0256 & 1.86 & 1.46 & \\
\hline & 0.0540 & 0.0571 & 2.87 & 2.18 & \\
\hline & 0.0890 & 0.0977 & 3.83 & 2.92 & \\
\hline \multirow[t]{11}{*}{$\mathrm{H}_{2} \mathrm{O}(1)+3-\mathrm{mpy}(2)$} & 0.0071 & 0.0072 & 0.5 & 1.49 & \multirow[t]{11}{*}{ Visual } \\
\hline & 0.0089 & 0.0090 & 0.5 & 1.87 & \\
\hline & 0.0120 & 0.0121 & 1.0 & 1.27 & \\
\hline & 0.0185 & 0.0188 & 1.0 & 1.98 & \\
\hline & 0.0253 & 0.0260 & 1.0 & 2.75 & \\
\hline & 0.0403 & 0.0420 & 1.5 & 3.02 & \\
\hline & 0.0488 & 0.0513 & 1.5 & 3.72 & \\
\hline & 0.0580 & 0.0616 & 2.0 & 3.39 & \\
\hline & 0.0663 & 0.0710 & 2.0 & 3.95 & \\
\hline & 0.0845 & 0.0923 & 2.0 & 5.25 & \\
\hline & 0.1035 & 0.1154 & 2.0 & 6.74 & \\
\hline \multirow[t]{13}{*}{$\mathrm{H}_{2} \mathrm{O}(1)+4-m p y(2)$} & 0.0063 & 0.0063 & 1.0 & 0.66 & \multirow[t]{13}{*}{ Visual } \\
\hline & 0.0077 & 0.0078 & 1.0 & 0.81 & \\
\hline & 0.0097 & 0.0098 & 1.0 & 1.02 & \\
\hline & 0.0131 & 0.0133 & 1.0 & 1.39 & \\
\hline & 0.0202 & 0.0206 & 1.0 & 2.17 & \\
\hline & 0.0277 & 0.0285 & 1.5 & 2.02 & \\
\hline & 0.0299 & 0.0308 & 1.5 & 2.19 & \\
\hline & 0.0404 & 0.0421 & 2.0 & 2.27 & \\
\hline & 0.0517 & 0.0545 & 2.0 & 2.98 & \\
\hline & 0.0620 & 0.0661 & 2.0 & 3.65 & \\
\hline & 0.0777 & 0.0842 & 2.0 & 4.75 & \\
\hline & 0.0933 & 0.1029 & 2.0 & 5.92 & \\
\hline & 0.1038 & 0.1158 & 2.5 & 5.41 & \\
\hline
\end{tabular}


Table 1 continued

\begin{tabular}{llllll}
\hline System & $x_{2}{ }^{\mathrm{a}}$ & $X_{2}{ }^{\mathrm{b}}$ & $\Delta T(\mathrm{~K})$ & $\alpha$ & Method \\
\hline $\mathrm{H}_{2} \mathrm{O}(1)+2$-mpy (2) & 0.0102 & 0.0103 & 1.71 & 0.63 & DSC \\
& 0.0251 & 0.0257 & 2.26 & 1.21 & \\
& 0.0501 & 0.0527 & 3.14 & 1.83 & \\
& 0.0999 & 0.1110 & 4.16 & 3.10 & \\
$\mathrm{H}_{2} \mathrm{O}(1)+2.6$-dmpy (2) & 0.0101 & 0.0102 & 1.37 & 0.78 & DSC \\
& 0.0255 & 0.0262 & 1.58 & 1.76 & \\
& 0.0501 & 0.0527 & 2.31 & 2.49 & \\
& 0.1001 & 0.1112 & 3.79 & 3.41 & \\
\hline
\end{tabular}

a $x_{2}-$ mole fraction of the amine

${ }^{\mathrm{b}} \mathrm{X}_{2}-$ mole fraction of the complex (Eq. 2)

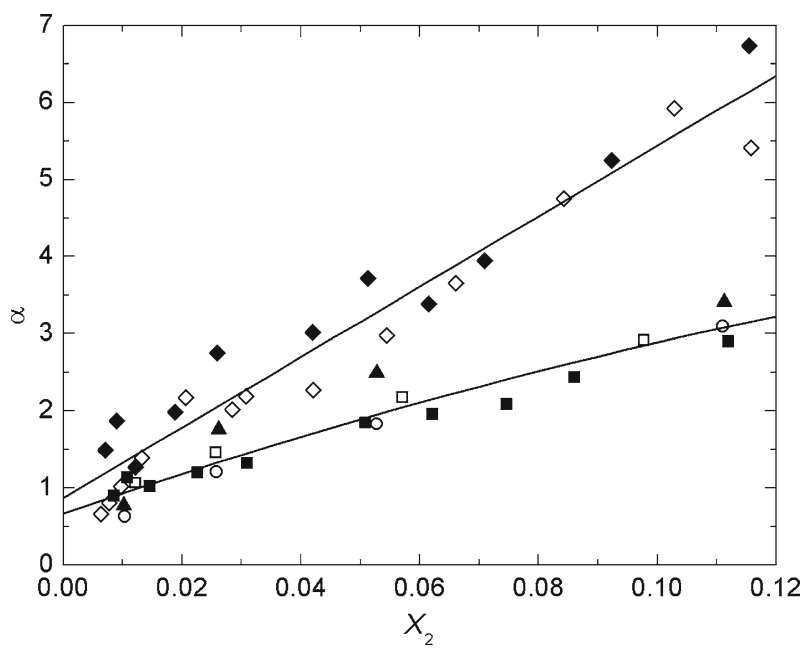

Fig. 3 Degrees of association of the pyridine and its methyl derivatives monohydrates as functions of their mole fraction $\left(X_{2}\right)$ : filled square-pyridine, open square-pyridine [9], filled triangle-2,6dimethylpyridine, filled diamond -3-methylpyridine, open diamond-4-methylpyridine, open circle2-methylpyridine

from relatively strong Keesom interactions between 4-methylpyridine molecules, while the attractions between less polar pyridine molecules are weaker. The dipole moments of 2-methylpyridine and 2,6-dimethylpyridine molecules are even smaller than that of pyridine. That would explain similar association numbers of the pyridine, 2-methylpyridine, and 2,6-trimethylpyridine hydrates. Stronger O-H...N bonds in the latter system may cause slightly higher association numbers due to co-operative interactions. It remains unexplained, however, why the association numbers of the 3and 4-methylpyridine hydrates are pretty much the same. One should expect those of the latter to be larger, since the molecules of 3-methylpyridine have a smaller dipole 
Table 2 Association energies of the 1:1 complexes of pyridine and its methyl derivatives with water, $E$, [4] and characteristics of the amine molecules: polarizability volumes $\alpha^{\prime}$ and dipole moments $\mu$

\begin{tabular}{llll}
\hline & $E\left(\mathrm{~kJ} \cdot \mathrm{mol}^{-1}\right)$ & $\alpha^{\prime}\left(\AA^{3}\right)$ & $\mu(\mathrm{D})$ \\
\hline Pyridine & 18.4 & $9.5^{\mathrm{a}}$ & $2.26^{\mathrm{a}}$ \\
2-Methylpyridine & 20.0 & $11.5^{\mathrm{b}}$ & $1.72-1.92^{\mathrm{a}}$ \\
2,6-Dimethylpyridine & 21.2 & $13.5^{\mathrm{c}}$ & $1.78^{\mathrm{d}}$ \\
4-Methylpyridine & 19.2 & $11.5^{\mathrm{b}}$ & $2.57^{\mathrm{a}}$ \\
3-Methylpyridine & 19.3 & $11.5^{\mathrm{b}}$ & $2.30^{\mathrm{a}}$ \\
\hline
\end{tabular}

Polarizability volumes calculated from the densities and refractive indices

a $[14]$

b $[15]$

c [16]

d [17]

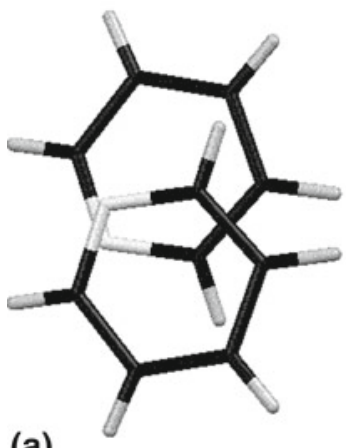

(a)

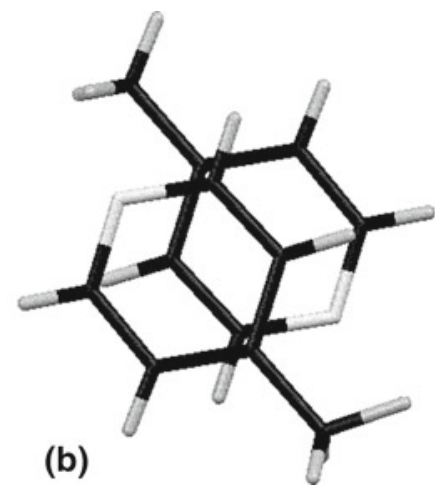

Fig. 4 Sandwich structures due to interactions between rings in the (a) solid trihydrates of pyridine and (b) 4-methylpyridine. Water molecules were omitted for picture clarity. Picture generated using Mercury 2.3 program from the data reported in the Cambridge Structural Database [18]

moment. It is, however, a general tendency that binary mixtures of water with 3- and 4-methylpyridine have similar thermodynamic properties, e.g., excesses of the Gibbs energy and entropy [19], enthalpy [19-21], molar volume, and isentropic compressibility [15,22-24].

The anti-parallel arrangement of the aromatic rings, characteristic of the 4-methypyridine solid trihydrate, has also been observed in crystals of 2,6-dimethylpyridine $\mathrm{N}$-oxide monohydrate. In that crystal, the planar aromatic rings are arranged in a sandwich-herringbone fashion, while water molecules form bridges between the oxygen atoms of the $\mathrm{N}$-oxide [25]. The $\mathrm{N} \rightarrow \mathrm{O}$ moiety both withdraws electrons and imposes a permanent dipole to the molecule. That strengthens the $\pi-\pi$ and dipoledipole interactions. In the hydrate of 2,6-dimethylpyrine, the ring-ring interactions are undoubtedly weaker, because of the lack of $\mathrm{N} \rightarrow \mathrm{O}$ moiety. However, one may expect that the ring-ring interaction energy is sufficient to cause molecular arrangement similar to that in pyridine trihydrate. 


\section{Conclusion}

The above considerations may be summarized in the following way. Pyridine and its methyl derivatives form hydrates in an aqueous environment. The latter associate, and the association number increases with an increase of the amine concentration. The hydrates of 3-and 4-methylpyridine show a stronger tendency to association than those of pyridine, 2-methylpyridine, and 2,6-dimethylpyridine. In the association, effects of the hydrogen bonds co-operativity and van der Waals interactions are revealed.

Acknowledgments The experimental part of this study was performed at the Laboratoire de Chimie et de Méthodologies pour l'Environment, Université Paul Verlaine-Metz, France. The authors wish to thank Prof. Marek Rogalski of LCME for inspiring discussions. K.S. gratefully acknowledges support from the LLP-Erasmus programme.

Open Access This article is distributed under the terms of the Creative Commons Attribution Noncommercial License which permits any noncommercial use, distribution, and reproduction in any medium, provided the original author(s) and source are credited.

\section{References}

1. F. Franks, Water (The Royal Society of Chemistry, London, 1983)

2. P.R. Rablen, J.W. Lockman, W.J. Jorgensen, J. Phys. Chem. A 102, 3782 (1998)

3. W. Marczak, J.K. Lehmann, A. Heintz, J. Chem. Thermodyn. 35, 269 (2003)

4. L. Pápai, G. Jancsó, J. Phys. Chem. A 104, 2132 (2000)

5. W. Marczak, K. Kiełek, B. Czech, H. Flakus, M. Rogalski, Phys. Chem. Chem. Phys. 11, 2668 (2009)

6. W. Marczak, A. Heintz, M. Bucek, J. Chem. Thermodyn. 36, 575 (2004)

7. D. Mootz, H.-G. Wussow, J. Chem. Phys. 75, 1517 (1981)

8. M. Born, D. Mootz, S. Schaefgen, Z. Naturforsch. B 50, 101 (1995)

9. A.J. Glessner, A.L. Myers, J. Chem. Eng. Data 16, 181 (1971)

10. P.W. Atkins, J. Paula, Atkins' Physical Chemistry, 8th edn. (Oxford University Press, Oxford, 2006), p. 136

11. L. Almásy, Thesis (Eötvös Loránd University, Budapest, and Université Pierre et Marie Curie, Paris, 2002)

12. B. Czech, W. Marczak, unpublished data

13. W. Marczak, B. Czech, L. Almásy, unpublished results

14. Poradnik fizykochemiczny (WNT Warszawa, 1974), p. B135

15. S. Ernst, W. Marczak, A. Kadziołka, Bull. Pol. Acad. Sci. Chem. 42, 83 (1994)

16. S. Ernst, W. Marczak, D. Kmiotek, J. Chem. Eng. Data 41, 128 (1996)

17. H. Borsdorf, M. Rudolph, Int. J. Ion Mobil. Spectrom. 3, 1 (2000)

18. Cambridge Crystallographic Data Centre Database, CSD Version 5.31 (2009)

19. J.-I. Abe, K. Nakanishi, H. Touhara, J. Chem. Thermodyn. 10, 483 (1978)

20. W. Wóycicki, Bull. Acad. Pol. Sci. Ser. Sci. Chim. 15, 613 (1967)

21. W. Marczak, E. Giera, J. Chem. Thermodyn. 30, 241 (1998)

22. S. Ernst, W. Marczak, Bull. Pol. Acad. Sci. Chem. 40, 307 (1991)

23. S. Ernst, W. Marczak, Bull. Pol. Acad. Sci. Chem. 43, 259 (1995)

24. W. Marczak, S. Ernst, Bull. Pol. Acad. Sci. Chem. 46, 389 (1998)

25. J.G. Planas, G.G. Mohamed, R. Sillanpää, R. Kivekäs, F. Teixidor, C. Viñas, J. Mol. Struct. 787, 21 (2006) 